\title{
Mitokyne: A Ratiometric Raman Probe for Mitochondrial pH
}

\author{
Liam T. Wilson, William J. Tipping, Corinna Wetherill, Zoë Henley, Karen Faulds, * Duncan Graham,* \\ Simon P. Mackay, and Nicholas C. O. Tomkinson*
}

Cite This: https://doi.org/10.1021/acs.analchem.1c03075

Read Online

ACCESS | Lلll Metrics \& More | 回 Article Recommendations

ABSTRACT: Mitochondrial $\mathrm{pH}\left(\mathrm{pH}_{\text {mito }}\right)$ is intimately related to mitochondrial function, and aberrant values for $\mathrm{pH}_{\text {mito }}$ are linked to several disease states. We report the design, synthesis, and application of mitokyne 1 - the first small molecule $\mathrm{pH}_{\text {mito }}$ sensor for stimulated Raman scattering (SRS) microscopy. This ratiometric probe can determine subtle changes in $\mathrm{pH}_{\text {mito }}$ in response to external stimuli and the inhibition of both the electron transport chain and ATP synthase with small molecule inhibitors. In addition, 1 was also used to monitor mitochondrial dynamics in a time-resolved manner with subcellular spatial resolution during mitophagy providing a powerful tool for dissecting the molecular and cell biology of this critical organelle.

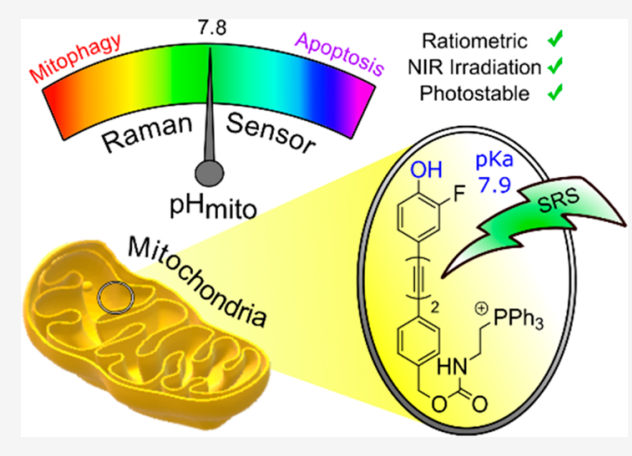

timulated Raman scattering (SRS) microscopy is a power$\checkmark$ ful, cutting-edge technology for visualizing endogenous cellular biomolecules in a label-free manner with excellent spatial resolution $^{1}$ and video rate image acquisition. ${ }^{2}$ The recent advent of commercial vendors of instruments for SRS has accelerated the integration of this spectroscopic method into pharmaceutical and drug discovery research. ${ }^{3,4}$ The technique can be used to track and monitor the cellular milieu and its response to external stimuli in a spatiotemporal manner, and in combination with chemical probes, it can be used to image the distribution of drugs, $^{3-5}$ natural products, ${ }^{6-9}$ sugars, $^{10-12}$ and lipids. ${ }^{13-15}$ Raman-active tags have also been metabolically incorporated into nucleic acids and proteins significantly expanding the potential uses of this instrumentation. ${ }^{16}$ The majority of probes reported so far for SRS imaging possess constant signal intensity and frequency, which limits their applications to staining. ${ }^{17-20}$ An exciting yet overlooked area of Raman imaging is the development of reversible sensors which permit the quantification and monitoring of cellular dynamics. This type of probe would be crucial for exploiting the full potential of SRS imaging in chemical biology and pharmaceutical research. ${ }^{21}$

Mitochondria are a structurally unique organelle responsible for cellular adenosine triphosphate (ATP) production. Resting mitochondrial $\mathrm{pH}\left(\mathrm{pH}_{\text {mito }}\right)$ is typically alkaline $(\mathrm{pH} \sim 8.0)$ as protons are pumped out of the inner mitochondrial matrix via the electron transport chain (ETC), providing a proton motive force $\left(\psi_{\mathrm{H}}^{+}\right)$which drives ATP synthase. ${ }^{22-24} \psi_{\mathrm{H}}^{+}$also acts to regulate $\mathrm{Ca}^{2+}$ homeostasis, which, in turn, regulates elements of the tricarboxylic acid (TCA) cycle. ${ }^{25-27}$ Alkalinization of $\mathrm{pH}_{\text {mito }}$ is associated with apoptosis, ${ }^{28}$ while acidification is associated with mitochondrial autophagy (mitophagy). ${ }^{27,29}$ Aberrant levels of mitophagy are associated with cardiovascular disease, ${ }^{30}$ Parkinson's disease, ${ }^{31}$ Alzheimer's disease, ${ }^{32}$ and cancer. ${ }^{33}$ It is also likely that multiple indications associated with mitochondrial dysfunction have yet to be identified. As such, sensors to determine $\mathrm{pH}_{\text {mito }}$ represent highly valuable tools for the study of human physiology and pathology and drug development. Small molecule fluorescent sensors for $\mathrm{pH}_{\text {mito }}$ have been reported; however, challenges exist in their application. Those probes which are non-ratiometric ${ }^{27,34,35}$ are limited in their capacity for quantitative measurements due to artifacts arising from changes in probe distribution, concentration, or instrument setup. Those probes which are ratiometric ${ }^{36-40}$ are limited in their capacity for multiplexing by their intrinsically broad spectral absorption and emission profiles. The development of a ratiometric $\mathrm{pH}_{\text {mito }}$ sensor for SRS imaging could simultaneously address both issues.

Within this article, we report the design, synthesis, and application of mitokyne 1 -a small molecule $\mathrm{pH}_{\text {mito }}$ sensor for SRS microscopy (Figure 1). This ratiometric probe is able to determine subtle changes in $\mathrm{pH}_{\text {mito }}$ in response to external stimuli, including the inhibition of both the electron transport chain and ATP synthase, as well as monitoring mitochondrial dynamics during mitophagy in a time-resolved manner.

In designing mitokyne $\mathbf{1}$, we reasoned that a $\mathrm{pH}_{\text {mito }}$ sensor required a strong, bioorthogonal Raman band which underwent a Raman shift upon ionization of a conjugated functional group to enable ratiometric analysis. In our previous work, we identified that bisarylbutadiynes with ionizable head groups

Received: July 21, 2021

Accepted: August 26, 2021 


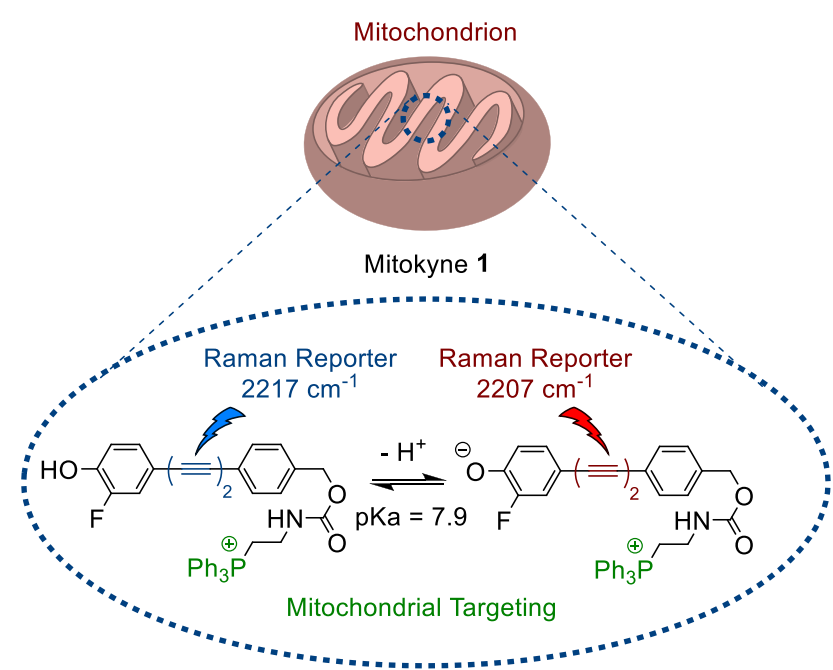

Figure 1. Design of mitochondrial $\mathrm{pH}$ sensor mitokyne $\mathbf{1 .}$

were suitable for this purpose. ${ }^{41} \mathrm{~A} \mathrm{pH}_{\text {mito }}$ sensor would also require a $\mathrm{p} K_{\mathrm{a}}$ close to 8.0 , for accuracy in the $\mathrm{pH}_{\text {mito }}$ range, and a mitochondrial targeting group. ${ }^{42-45}$ This led to the structure shown in Figure 1-a phenolic bisarylbutadiyne with a $\mathrm{p} K_{\mathrm{a}}$ of 7.9 and a mitochondria-targeting triphenylphosphonium group linked via a benzylic carbamate.

Our investigations began with a simple, effective, and scalable synthesis which provided access to suitable quantities of material for the Raman investigation (Scheme 1). Silyl-deprotection/ Glaser-Hay coupling of a mixture of $\mathbf{2}$ and $\mathbf{3}$ (syntheses detailed in the Supporting Information) generated bisarylbutadiyne $\mathbf{4}$ in $51 \%$ yield. This was followed by carbamate formation, reacting

\section{Scheme 1. Synthesis of Mitokyne 1}

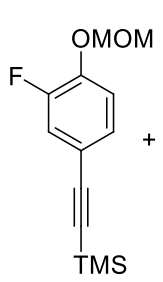<smiles>CC(C)(C)C#Cc1ccc(CO)cc1</smiles>

1) $\mathrm{K}_{2} \mathrm{CO}_{3}$ (5 eq per TMS) $\mathrm{MeOH}: \mathrm{CH}_{2} \mathrm{Cl}_{2}(1: 1), \mathrm{rt}, 3 \mathrm{~h}$

2) $\mathrm{CuCl}(1 \mathrm{eq})$, TMEDA (2 eq) $\mathrm{Me}_{2} \mathrm{CO}: \mathrm{CH}_{2} \mathrm{Cl}_{2}(5: 1)$, air, rt, $3 \mathrm{~h}$ TMS $23(3 \mathrm{eq})$

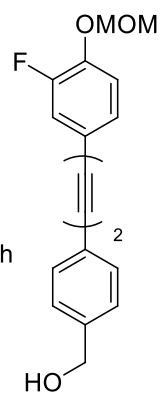

$4(51 \%)$

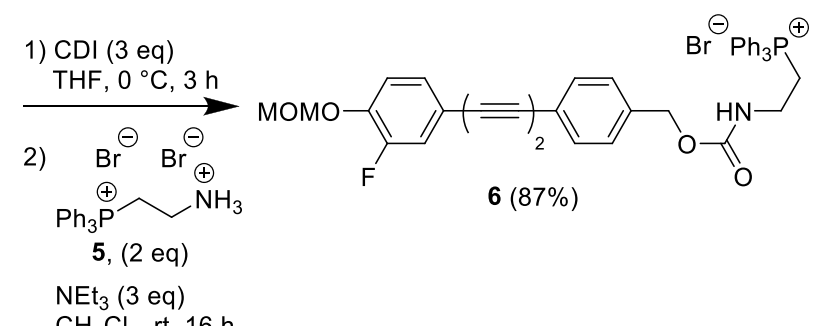

$\mathrm{CH}_{2} \mathrm{Cl}_{2}, \mathrm{rt}, 16 \mathrm{~h}$

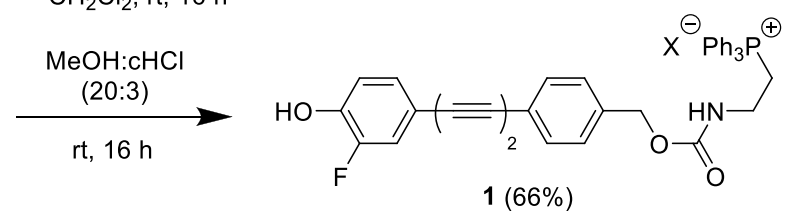

the pendant benzylic alcohol of 4 with CDI, and then addition of amine 5 to generate carbamate 6 in $87 \%$ yield. Finally, deprotection of the phenolic headgroup with concentrated $\mathrm{HCl}$ in $\mathrm{MeOH}$ afforded mitokyne 1 in $66 \%$ yield.

The spectroscopic properties of mitokyne $\mathbf{1}$ are reported in Figure 2. Figure 2A shows a Raman spectrum of $\mathbf{1}$, indicating the
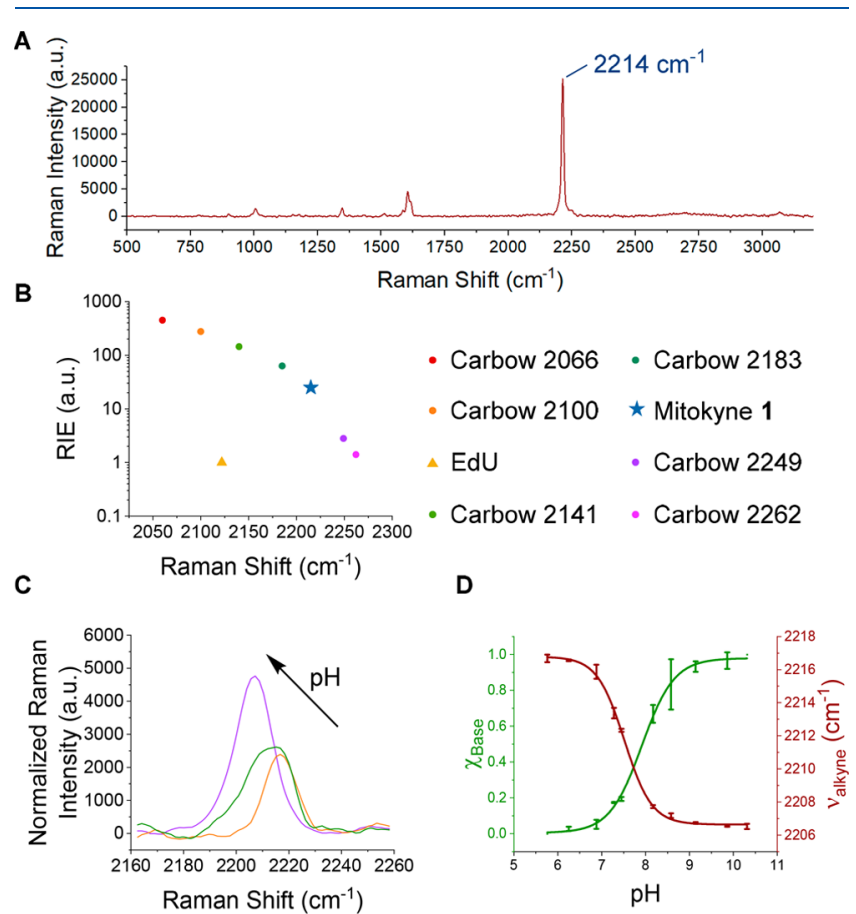

- $\mathrm{pH} 5.7-\mathrm{pH} 7.5-\mathrm{pH} 10.3$

$v_{\max }=2216.8 \quad \mathrm{pKa}=7.91 \pm 0.03$ $v_{\min }=2206.6$

Figure 2. Raman spectroscopy of mitokyne 1 (532 nm). (A) Raman spectrum of mitokyne 1 in solid form ( $0.1 \%, 1$ s, 20 accumulations). (B) RIE (relative intensity vs EdU) and alkyne Raman shift of 1 relative to literature alkyne probes ( $\log$ scale, $100 \%, 1 \mathrm{~s}, 20$ accumulations). ${ }^{42,46}$ (C) Alkyne regions of $\mathbf{1}$ in solution at a range of $\mathrm{pH}$ values $(100 \mu \mathrm{M}$, $30 \%$ wt EtOH/Britton-Robinson buffers, $I=0.2)$, normalized to the solvent peak at $1455 \mathrm{~cm}^{-1}(100 \%, 1 \mathrm{~s}, 20$ accumulations). (D) Plot of

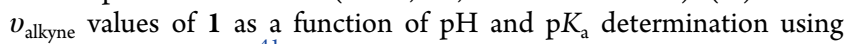
curve-fitting analysis. $^{41}$

high intensity of the alkyne band at $2214 \mathrm{~cm}^{-1}$ relative to other vibrational bands. The intensities of alkyne probes are typically evaluated by their relative intensities versus 5-ethynyl-2'deoxyuridine (EdU, RIE). ${ }^{46}$ We collected Raman spectra of mitokyne 1 and EdU in DMSO solution and determined the RIE of the neutral form of $\mathbf{1}$ to be 24, indicating high Raman intensity. Figure 2B shows a plot of RIE vs Raman shift of $\mathbf{1}$ alongside a series of literature alkyne probes with resolvable stretching frequencies. The data from which this plot derives can be found in Table S1. The plot highlights the potential for multiplexing 1 with a considerable array of Raman probes, while also being compatible with commercial fluorescent probes.

The $\mathrm{pH}$-responsive nature of the alkyne band in $\mathbf{1}$ was investigated in buffered solutions $(100 \mu \mathrm{M}, 30 \%$ wt EtOH/ Britton-Robinson buffer, $I=0.2$ ). Figure $2 \mathrm{C}$ shows the alkyne regions of Raman spectra of $\mathbf{1}$ in solutions at different $\mathrm{pH}$ values, showing the redshift of the alkyne band upon increasing $\mathrm{pH}$. At higher $\mathrm{pH}$, the phenol group of $\mathbf{1}$ is deprotonated. The resulting phenolate anion is conjugated with the butadiyne Raman reporter, resulting in a redshift of the Raman band upon increasing $\mathrm{pH}$. This redshift of the alkyne peak is also 
accompanied by an increase in the Raman scattering cross section. The combined spectral range encompassed by the alkyne bands of both ionization states of the probe was ca. 2190-2230 $\mathrm{cm}^{-1}$. This narrow bandwidth indicated that multiplex imaging with other alkyne probes such as those highlighted in Figure 2B, as well as fluorescent probes, should be facile. Peak deconvolution analysis ${ }^{41}$ was used to estimate the mole fraction of the conjugate base of $1\left(\chi_{\text {Base }}\right)$ from Raman spectra at a range of $\mathrm{pH}$ values. This enabled determination of the $\mathrm{p} K_{\mathrm{a}}$ of 1 , which was found to be $7.91 \pm 0.03$ under the conditions of solvent, temperature, and ionic strength studied (Figure 2D, Figure S1). This $\mathrm{p} K_{\mathrm{a}}$ appeared ideal for measurement of mitochondrial $\mathrm{pH}$, as it indicated $\mathbf{1}$ was most responsive to changes in $\mathrm{pH}$ in the typical mitochondrial $\mathrm{pH}$ range. ${ }^{24}$

To determine whether mitokyne 1 accumulated within the mitochondria of cells, HeLa cells were treated with mitokyne 1 $\left(10 \mu \mathrm{M}, 30 \mathrm{~min}\right.$ ) and mitotracker $\operatorname{red}^{47}$ (MTR, $100 \mathrm{nM}$, $30 \mathrm{~min}$ ), then imaged by tandem SRS-fluorescence microscopy (Figure 3). SRS imaging at 2930 and $2850 \mathrm{~cm}^{-1}$ indicated the

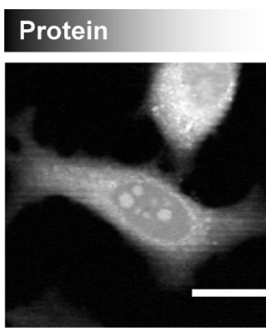

\section{Lipid}

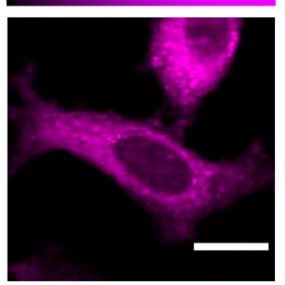

Off-Resonance

\section{Mitokyne}
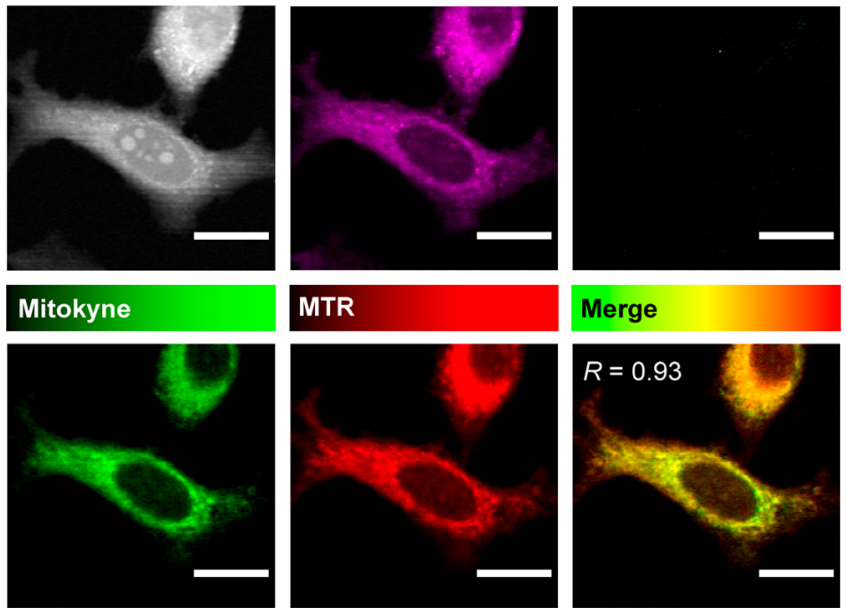

Figure 3. Tandem SRS-fluorescence imaging of HeLa cells treated with mitokyne $1(10 \mu \mathrm{M}, 30 \mathrm{~min})$ and MTR (100 nM, $30 \mathrm{~min})$. Fluorescence images were acquired first $\left(\lambda_{\mathrm{ex}}=561 \mathrm{~nm}\right.$, collection $=$ $580-620 \mathrm{~nm}$ ) followed by SRS images at $2225 \mathrm{~cm}^{-1}$ ( $\left.\mathrm{C} \equiv \mathrm{C}, \mathbf{1}\right), 2125$ $\mathrm{cm}^{-1}$ (off-resonance), $2930 \mathrm{~cm}^{-1}\left(\mathrm{CH}_{3}\right.$, protein) and $2850 \mathrm{~cm}^{-1}\left(\mathrm{CH}_{2}\right.$, lipid). All images were acquired at $512 \times 512$ pixels, $20 \mu$ s pixel dwell time, with false colors applied to different detection wavelengths in ImageJ. All scale bars represent $20 \mu \mathrm{m}$. The merged image of mitokyne $\mathbf{1}$ and MTR signal was generated in ImageJ, and the Pearson's $R$ value was determined using the Coloc2 tool.

distribution of endogenous proteins and lipids, respectively, allowing identification of cell boundaries and the location of nuclei. The signal at $2225 \mathrm{~cm}^{-1}$ indicated the distribution of mitokyne 1 within the cell, which was confirmed by the lack of signal in the off-resonance channel at $2125 \mathrm{~cm}^{-1}$. A fluorescence signal arising from MTR and a SRS signal arising from 1 appeared nearly identical in distribution, which was confirmed by the merged image. Colocalization analysis using ImageJ gave a Pearson's $R$ value for these two images of 0.93 - a very strong correlation confirming that mitokyne $\mathbf{1}$ is mitochondrially localized.

We assessed the photostability of 1 by treating HeLa cells with $1(10 \mu \mathrm{M}, 30 \mathrm{~min})$ and MTR (100 $\mathrm{nM}, 30 \mathrm{~min})$ and acquiring eight consecutive images of both probes. The signal for 1 remained constant, whereas the MTR signal decreased rapidly after one acquisition (Figure S2). Mitokyne $\mathbf{1}$ therefore allows for time-lapsed imaging of mitochondrial dynamics without the signal degradation observed with MTR. We also considered the cytotoxicity of 1 . HeLa cells were treated with DMSO control $(6 \mathrm{~h})$ or $1(10 \mu \mathrm{M}, 6 \mathrm{~h})$. Cells were counted by trypan blue exclusion, finding no significant difference between the control and test samples and indicating minimal toxicity of $\mathbf{1}$ (Figure S3).

We next aimed to apply mitokyne 1 to the quantification of $\mathrm{pH}_{\text {mito }}$ in HeLa cells. First, we calibrated the probe by treating HeLa cells with $1(10 \mu \mathrm{M}, 30 \mathrm{~min})$ and then treating with buffer solutions containing the ionophores nigericin $(10 \mu \mathrm{M})$ and monensin $(10 \mu \mathrm{M})$ to set $\mathrm{pH}_{\text {mito }}$ to known values. ${ }^{37,48}$ The cells were then imaged by SRS microscopy at $2230 \mathrm{~cm}^{-1}$ (neutral 1 ) and $2216 \mathrm{~cm}^{-1}$ (ionized 1). These Raman shifts were determined to be optimal for ratiometric analysis from wavelength scans of mitokyne-treated HeLa cells at $\mathrm{pH} 6.0$ and 8.5 (Figure S8). It is noteworthy that the alkyne detection wavelengths were slightly blueshifted in SRS compared to spontaneous Raman, and the origin of this effect remains uncertain. Figure 4A shows representative false-color images of the 2230 and $2216 \mathrm{~cm}^{-1}$ channels of HeLa cells at $\mathrm{pH}$ values ranging from 6.5 to 9.0. Pseudocolored ratiometric images of the $2230 / 2216 \mathrm{~cm}^{-1}$ intensity ratios are also shown, indicating a clear change in the ratio as a function of $\mathrm{pH}$.

Figure 4B shows a plot of average $2230 / 2216 \mathrm{~cm}^{-1}$ ratios from within cells as a function of $\mathrm{pH}$. These values represent the average from three sets of 2230/2216 $\mathrm{cm}^{-1}$ images \pm standard deviation (SD). The plot was fitted to a Boltzmann function in OriginPro2018, which served as a calibration curve with which to relate the $2230 / 2216 \mathrm{~cm}^{-1}$ ratio to $\mathrm{pH}_{\text {mito }}$ values going forward. Figure $4 \mathrm{C}$ shows that the average $\mathrm{pH}_{\text {mito }}$ value of $\mathrm{HeLa}$ cells treated with mitokyne $1(10 \mu \mathrm{M}, 30 \mathrm{~min})$ only (control) was $7.84 \pm 0.07$ (nine sets of images, \pm SD), a value consistent with previous reports from fluorescent $\mathrm{pH}_{\text {mito }}$ sensors. ${ }^{27,37}$ This result served as further confirmation of the mitochondrial localization of $\mathbf{1}$.

Given that $\mathrm{pH}_{\text {mito }}$ is inextricably linked to cellular metabolism via the ETC, we reasoned that nutrient starvation would also induce mitochondrial acidification. HeLa cells were treated with mitokyne $1(10 \mu \mathrm{M}, 30 \mathrm{~min})$ and then incubated in media containing no glucose, pyruvate, serum, or glutamine. As expected, when imaged by SRS microscopy, these cells exhibited a relatively rapid drop in $\mathrm{pH}_{\text {mito }}$ (Figure 5A). Ratiometric 2230/ $2216 \mathrm{~cm}^{-1}$ images collected prior to starvation and after 10, 20, and $30 \mathrm{~min}$ of starvation show a significant change in ratio. After $30 \mathrm{~min}, \mathrm{pH}_{\text {mito }}$ had reduced to $7.30 \pm 0.18$. These results are consistent with the arrest of proton pump activity across the inner mitochondrial membrane in the absence of an energy source. This experiment, along with the calibration process, was repeated via spontaneous Raman microscopy (Figure S4) with consistent results. This indicated that, although SRS imaging is necessary to achieve the desired subcellular resolution to image mitochondrial dynamics, $\mathbf{1}$ is still able to determine average $\mathrm{pH}_{\text {mito }}$ values using the more widely accessible technique of spontaneous Raman imaging.

Nutrient starvation causes mitochondrial acidification via mitophagy. ${ }^{27,37}$ To test whether mitokyne 1 could be used to monitor mitochondrial dynamics during mitophagy, HeLa cells were cotreated with mitokyne $1(10 \mu \mathrm{M}, 30 \mathrm{~min})$ and lysotracker red (LTR, $100 \mathrm{nM}, 30 \mathrm{~min}$ ), then starved of nutrients for 10, 20,30, and $40 \mathrm{~min}$ and imaged by tandem SRS/ fluorescence microscopy in the same cell population 
A

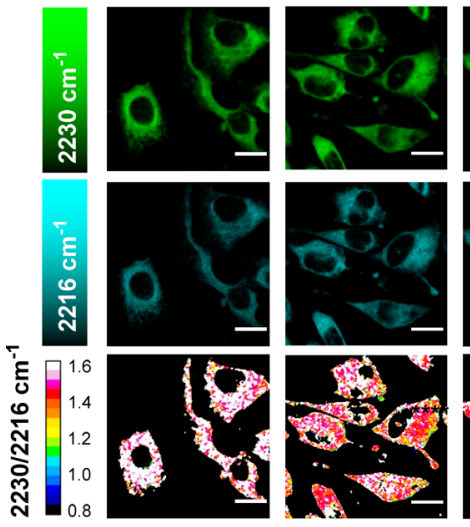
$\mathrm{pH} 7.5$
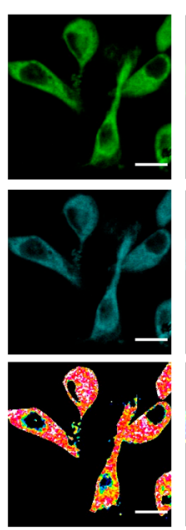
pH 8.0
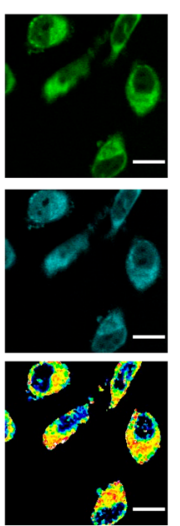

pH 8.5
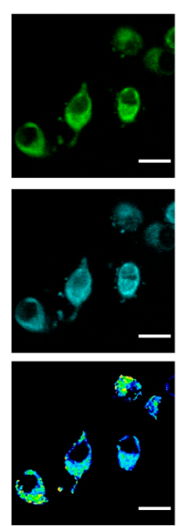

pH 9.0
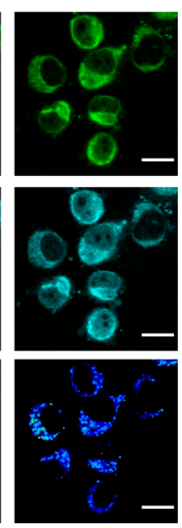

B

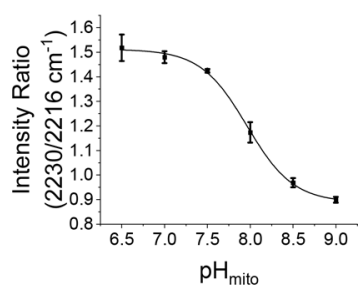

C

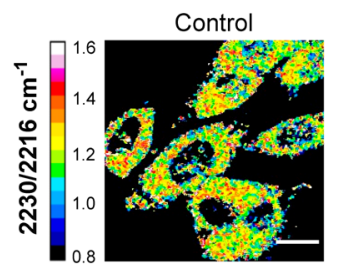

$\mathrm{pH} 7.84 \pm 0.07$

Figure 4. Calibration of mitokyne 1 in HeLa cells and measurement of HeLa cell $\mathrm{pH}_{\text {mito }}$. (A) HeLa cells were treated with $\mathbf{1}$ (10 $\mu \mathrm{M}$, $\left.30 \mathrm{~min}\right)$, clamped to discrete $\mathrm{pH}$ values using buffers containing the ionophores nigericin $(10 \mu \mathrm{M})$ and monensin $(10 \mu \mathrm{M})$, and imaged by SRS at 2230 and $2216 \mathrm{~cm}^{-1}$. False colors were applied to different detection wavelengths in ImageJ, and pseudocolored ratiometric images were produced using the image calculator tool. (B) Calibration plot of average $2230 / 2216 \mathrm{~cm}^{-1}$ ratio from within cells as a function of $\mathrm{pH}$ (average of three images, error bars $\pm \mathrm{SD}$ ). (C) Representative pseudocolored ratiometric $2230 / 2216 \mathrm{~cm}^{-1}$ image of HeLa cells treated with $1\left(10 \mu \mathrm{M}, 30 \mathrm{~min}\right.$, control). Reported pH $\mathrm{H}_{\text {mito }}$ value represents the average value from nine images $( \pm S D)$. All images were acquired at $512 \times 512$ pixels and $16 \mu$ s pixel dwell time. Scale bars represent $20 \mu \mathrm{m}$.

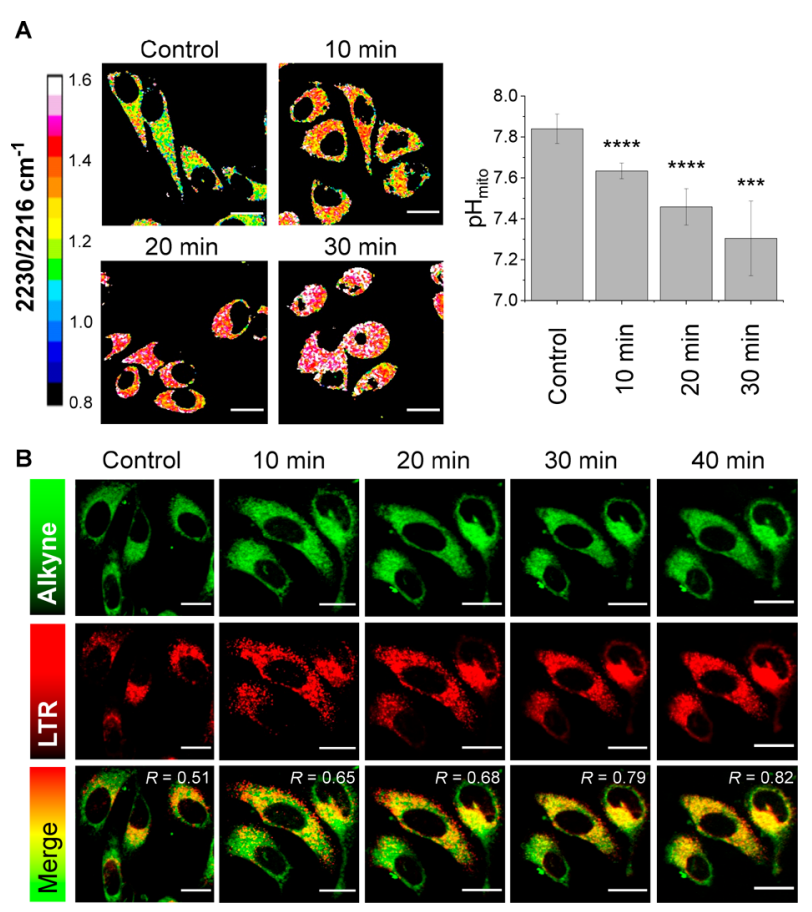

Figure 5. HeLa cell nutrient starvation. (A) Pseudocolored ratiometric $2230 / 2216 \mathrm{~cm}^{-1}$ images of HeLa cells treated with mitokyne $1(10 \mu \mathrm{M}$, $30 \mathrm{~min}$ ), then starved of glucose, glutamine, pyruvate, and serum for the indicated times. Graph indicates average $\mathrm{pH}_{\text {mito }}$ values derived from average cellular $2230 / 2216 \mathrm{~cm}^{-1}$ ratios in the images shown (10 cells, error bars \pm SD) $(* * * * p<0.0001, * * * p<0.001$, Student's $t$ test $)$. (B) Pseudocolored SRS $\left(2225 \mathrm{~cm}^{-1}, 1\right)$, fluorescence $\left(\lambda_{\mathrm{ex}}=561 \mathrm{~nm}\right.$, collection 580-620 nm, LTR), and merged images from HeLa cells treated with mitokyne $1(10 \mu \mathrm{M}, 30 \mathrm{~min})$ and LTR (100 $\mathrm{nM}, 30 \mathrm{~min})$, then starved of glucose, glutamine, pyruvate, and serum. All images were acquired at $512 \times 512$ pixels and $16 \mu$ s pixel dwell time. Scale bars represent $20 \mu \mathrm{m}$.

(Figure 5B). We found that the overlap between mitokyne $\mathbf{1}$ and LTR signal (as indicated by Pearson's $R$ value) increased over time, rising to a value of 0.82 after $40 \mathrm{~min}$, consistent with the degradation of mitochondria by lysosomes, i.e., mitophagy. ${ }^{49}$ This temporal analysis in a single cell population without loss of $\mathrm{C} \equiv \mathrm{C}$ signal demonstrates an advantage of a Raman-imaging approach, as photodegradation of MTR would not permit this type of analysis. To the best of our knowledge, this also represents the first time-resolved analysis of live cells using SRS at a fixed temperature of $37^{\circ} \mathrm{C}$.

It is established that the $\mathrm{pH}_{\text {mito }}$ gradient is driven by proton pumping in the ETC and oxidative phosphorylation. The ETC is composed of four complexes, responsible for a series of redox reactions, which ultimately result in the reduction of molecular oxygen to water (Figure 6A). Complexes I, III, and IV of the ETC are responsible for pumping protons out of the inner mitochondrial matrix and into the intermembrane space. The resulting electrochemical gradient, and re-entry of protons via ATP synthase (complex V) provides an energetic driving force for the production of ATP from adenosine diphosphate (ADP). ${ }^{22,24}$ Consequently, inhibition of ETC complexes I and III and ATP synthase would be expected to impact $\mathrm{pH}_{\text {mito }}$ and be detected by our mitochondrial probe. HeLa cells were treated with mitokyne 1 ( $10 \mu \mathrm{M}, 30 \mathrm{~min})$ followed by either rotenone (2 $\mu \mathrm{M}, 10 \mathrm{~min}$, complex I inhibitor), antimycin A ( $2 \mu \mathrm{M}, 10$ min, complex III inhibitor), or oligomycin ( $5 \mu \mathrm{M}, 10 \mathrm{~min}$, ATPsynthase inhibitor). Figure $6 \mathrm{~A}$ shows representative ratiometric $2230 / 2216 \mathrm{~cm}^{-1}$ images from these experiments. As expected, treatment with rotenone and antimycin $\mathrm{A}$ both induced mitochondrial acidification by $0.3-0.4 \mathrm{pH}$ units, consistent with the arrest of proton pump activity. Conversely, oligomycin treatment induced mitochondrial alkalinization by ca. $0.3 \mathrm{pH}$ units, indicating the arrest of proton re-entry via ATP synthase (Figure 6B). Acidification of mitochondria by rotenone and antimycin $A$ is consistent with previous qualitative reports of mitochondrial membrane potential (MMP) reduction in other cell lines, ${ }^{50-53}$ while oligomycin-induced mitochondrial alkalinization has been reported in $293 \mathrm{~T}$ cells. ${ }^{54}$ These results highlight the potential of mitokyne $\mathbf{1}$ as a powerful tool for interrogating 
A

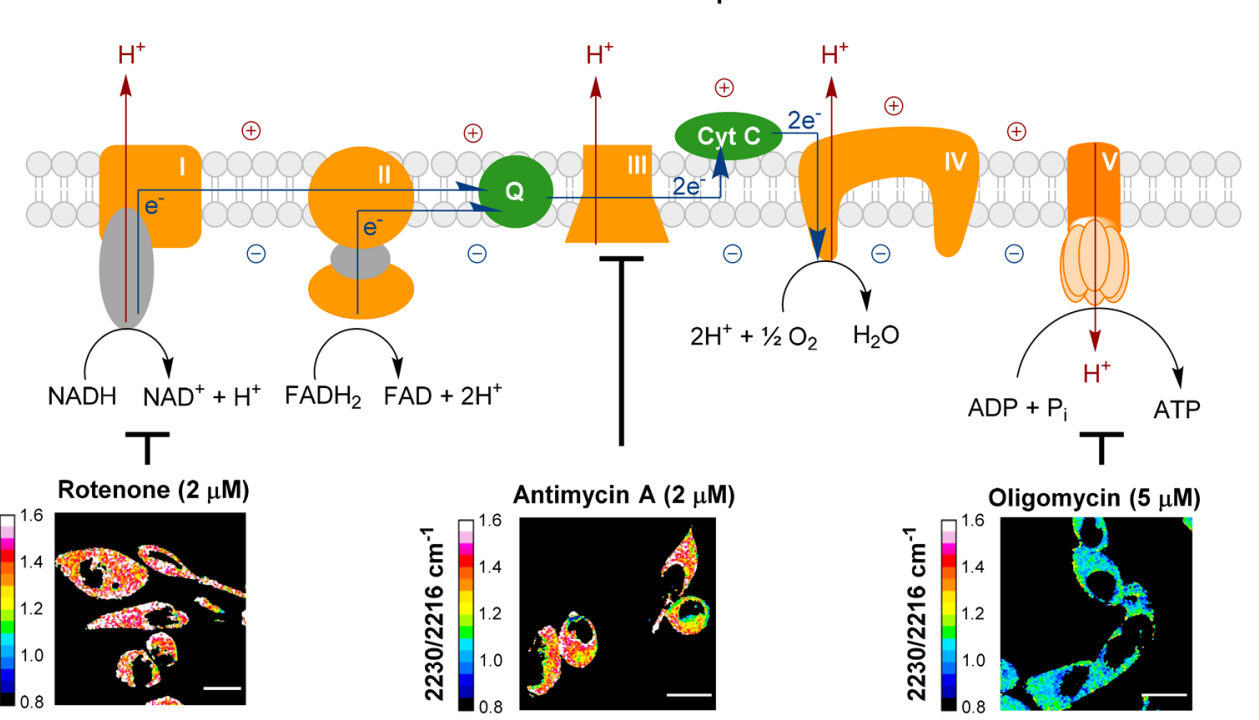

B

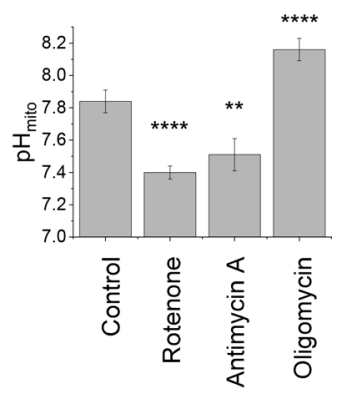

Inner Mitochondrial Matrix

Figure 6. Effect of inhibition of the ETC and ATP synthase on $\mathrm{pH}_{\text {mito }}$. HeLa cells were treated with mitokyne $\mathbf{1}(10 \mu \mathrm{M}, 30 \mathrm{~min})$, followed by either rotenone $(2 \mu \mathrm{M}, 10 \mathrm{~min})$, antimycin $\mathrm{A}(2 \mu \mathrm{M}, 10 \mathrm{~min})$, or oligomycin $(5 \mu \mathrm{M}, 10 \mathrm{~min})$, then imaged by SRS microscopy. All images were acquired at $512 \times 512$ pixels and $16 \mu$ s pixel dwell time. All scale bars are $20 \mu \mathrm{m}$. (A) Summary of the chemical transformations involved in the ETC and oxidative phosphorylation, showing representative ratiometric $2230 / 2216 \mathrm{~cm}^{-1}$ images from cells treated with the inhibitors rotenone, antimycin $A$, and oligomycin. (B) Graph of average $\mathrm{pH}_{\text {mito }}$ values observed in HeLa cells after treatment with mitokyne 1 only (control, nine images, \pm standard deviation), rotenone (four images, \pm standard deviation), antimycin A (four images, \pm standard deviation), and oligomycin (five images, \pm standard deviation) $(* * * * p<0.0001, * * * p<0.001, * * p<0.01$, Student's $t$ test $)$.

how $\mathrm{pH}_{\text {mito }}$ fluctuations are mechanistically associated with mitochondrial biochemistry.

We have reported the development of the first small molecule probe for the measurement of $\mathrm{pH}_{\text {mito }}$ via SRS microscopy. Mitokyne $\mathbf{1}$ is nontoxic, highly photostable, and possesses a $\mathrm{pH}$ chromic alkyne band which enables accurate ratiometric $\mathrm{pH}_{\text {mito }}$ measurement in live cells in a time-dependent manner. The narrow spectral resonances of mitokyne 1 enabled four-color cell imaging by tandem SRS-fluorescence microscopy, with clear potential for higher order multiplexing. The mitochondrial localization of the probe was confirmed in HeLa cells, and following calibration, mitokyne $\mathbf{1}$ was used to quantitatively measure changes in $\mathrm{HeLa} \mathrm{pH}_{\text {mito }}$ in response to nutrient starvation and treatment with inhibitors of the ETC and ATP synthase. With an optimized $\mathrm{p} K_{\mathrm{a}}$, the probe reliably reported on acidification and alkalinization events at the mitochondrial scale. The probe was also used to visualize mitochondrial dynamics with subcellular spatial resolution during mitophagy in a single cell population-owing to excellent photostability. These results demonstrate the ability of mitokyne $\mathbf{1}$ to be used as a tool for elucidating the roles of $\mathrm{pH}_{\text {mito }}$ in physiological and pathological cellular processes to advance collective understanding of cell biology.

\section{ASSOCIATED CONTENT}

\section{SI Supporting Information}

The Supporting Information is available free of charge at https://pubs.acs.org/doi/10.1021/acs.analchem.1c03075.

Analytical data, experimental procedures, and ${ }^{1} \mathrm{H},{ }^{19} \mathrm{~F}$ and ${ }^{13} \mathrm{C}$ NMR spectra for all compounds reported. Experimental procedures for all experiments presented in the article, representative workflows for the processing of SRS images, and additional Raman and SRS data pertaining to $\mathrm{p} K_{\mathrm{a}}$ determination and imaging of mitokyne 1. (PDF)

\section{AUTHOR INFORMATION}

\section{Corresponding Authors}

Karen Faulds - Centre for Molecular Nanometrology, WestCHEM, Department of Pure and Applied Chemistry, Technology and Innovation Centre, University of Strathclyde, Glasgow G1 1RD, United Kingdom; @ orcid.org/00000002-5567-7399; Email: karen.faulds@strath.ac.uk

Duncan Graham - Centre for Molecular Nanometrology, WestCHEM, Department of Pure and Applied Chemistry, Technology and Innovation Centre, University of Strathclyde, Glasgow G1 1RD, United Kingdom;

Email: duncan.graham@strath.ac.uk

Nicholas C. O. Tomkinson - Department of Pure and Applied Chemistry, University of Strathclyde, Glasgow G1 1XL, United Kingdom; (1) orcid.org/0000-0002-5509-0133;

Email: nicholas.tomkinson@strath.ac.uk

\section{Authors}

Liam T. Wilson - Department of Pure and Applied Chemistry, University of Strathclyde, Glasgow G1 1XL, United Kingdom

William J. Tipping - Centre for Molecular Nanometrology, WestCHEM, Department of Pure and Applied Chemistry, Technology and Innovation Centre, University of Strathclyde, Glasgow G1 1RD, United Kingdom

Corinna Wetherill - Centre for Molecular Nanometrology, WestCHEM, Department of Pure and Applied Chemistry, Technology and Innovation Centre, University of Strathclyde, Glasgow G1 1RD, United Kingdom 
Zoë Henley - GlaxoSmithKline Medicines Research Centre, Stevenage SG1 2NY, United Kingdom; (1) orcid.org/00000001-6686-3210

Simon P. Mackay - Strathclyde Institute of Pharmacy and Biomedical Science, University of Strathclyde, Glasgow G4 ORE, United Kingdom; (1) orcid.org/0000-0001-8000-6557

Complete contact information is available at:

https://pubs.acs.org/10.1021/acs.analchem.1c03075

\section{Author Contributions}

All authors have given approval to the final version of the manuscript.

Notes

The authors declare no competing financial interest.

\section{ACKNOWLEDGMENTS}

We thank the University of Strathclyde, the EPSRC (EP/ TR512114/1), and GlaxoSmithKline for financial support. We are extremely grateful to Prof. Richard C. Hartley and Prof. Stephen W. G. Tait for insightful and candid discussions on evaluating the cellular effects of mitokyne 1 .

\section{REFERENCES}

(1) Bi, Y.; Yang, C.; Chen, Y.; Yan, S.; Yang, G.; Wu, Y.; Zhang, G.; Wang, P. Light: Sci. Appl. 2018, 7, 81.

(2) Cheng, J.-X.; Xie, X. S. Science 2015, 350, aaa8870-aaa8870.

(3) El-Mashtoly, S. F. J. Med. Chem. 2020, 63, 3472-3474.

(4) Sepp, K.; Lee, M.; Bluntzer, M. T. J.; Helgason, G. V.; Hulme, A. N.; Brunton, V. G. J. Med. Chem. 2020, 63, 2028-2034.

(5) Gaschler, M. M.; Hu, F.; Feng, H.; Linkermann, A.; Min, W.; Stockwell, B. R. ACS Chem. Biol. 2018, 13, 1013-1020.

(6) Tipping, W. J.; Lee, M.; Serrels, A.; Brunton, V. G.; Hulme, A. N. Chem. Sci. 2017, 8, 5606-5615.

(7) Seidel, J.; Miao, Y.; Porterfield, W.; Cai, W.; Zhu, X.; Kim, S.-J.; Hu, F.; Bhattarai-Kline, S.; Min, W.; Zhang, W. Chem. Commun. 2019, $55,9379-9382$.

(8) Ueda, M.; Hayashi, K.; Egoshi, S.; Ishimaru, Y.; Takaoka, Y.; Yamakoshi, H.; Dodo, K.; Sodeoka, M. Org. Biomol. Chem. 2018, 16, 3348-3352.

(9) Ueda, M.; Egoshi, S.; Dodo, K.; Ishimaru, Y.; Yamakoshi, H.; Nakano, T.; Takaoka, Y.; Tsukiji, S.; Sodeoka, M. ACS Cent. Sci. 2017, $3,462-472$.

(10) Hu, F.; Chen, Z.; Zhang, L.; Shen, Y.; Wei, L.; Min, W. Angew. Chem., Int. Ed. 2015, 54, 9821-9825.

(11) Long, R.; Zhang, L.; Shi, L.; Shen, Y.; Hu, F.; Zeng, C.; Min, W. Chem. Commun. 2018, 54, 152-155.

(12) Moliner, F.; Knox, K.; Gordon, D.; Lee, M.; Tipping, W. J.; Geddis, A.; Reinders, A.; Ward, J. M.; Oparka, K.; Vendrell, M. Angew. Chem. 2021, 133, 7715-7720.

(13) Lee, H. J.; Zhang, W.; Zhang, D.; Yang, Y.; Liu, B.; Barker, E. L.; Buhman, K. K.; Slipchenko, L. V.; Dai, M.; Cheng, J.-X. Sci. Rep. 2015, 5, 7930.

(14) Hu, F.; Wei, L.; Zheng, C.; Shen, Y.; Min, W. Analyst 2014, 139, 2312-2317.

(15) Jamieson, L. E.; Greaves, J.; McLellan, J. A.; Munro, K. R.; Tomkinson, N. C. O.; Chamberlain, L. H.; Faulds, K.; Graham, D. Spectrochim. Acta, Part A 2018, 197, 30-36.

(16) Wei, L.; Hu, F.; Shen, Y.; Chen, Z.; Yu, Y.; Lin, C.-C.; Wang, M. C.; Min, W. Nat. Methods 2014, 11, 410-412.

(17) Zhao, Z.; Shen, Y.; Hu, F.; Min, W. Analyst 2017, 142, 40184029.

(18) Bakthavatsalam, S.; Dodo, K.; Sodeoka, M. RSC Chem. Biol. 2021, DOI: 10.1039/D1CB00116G.

(19) Adamczyk, A.; Matuszyk, E.; Radwan, B.; Rocchetti, S.; Chlopicki, S.; Baranska, M. J. Med. Chem. 2021, 64, 4396-4409.
(20) Li, Y.; Shen, B.; Li, S.; Zhao, Y.; Qu, J.; Liu, L. Adv. Biology 2021, 5, 2000184

(21) Hu, F.; Shi, L.; Min, W. Nat. Methods 2019, 16, 830-842.

(22) Llopis, J.; McCaffery, J. M.; Miyawaki, A.; Farquhar, M. G.; Tsien, R. Y. Proc. Natl. Acad. Sci. U. S. A. 1998, 95, 6803-6808.

(23) Abad, M. F. C.; Di Benedetto, G.; Magalhães, P. J.; Filippin, L.; Pozzan, T. J. Biol. Chem. 2004, 279, 11521-11529.

(24) Casey, J. R.; Grinstein, S.; Orlowski, J. Nat. Rev. Mol. Cell Biol. 2010, 11, 50-61.

(25) Crompton, M.; Heid, I. Eur. J. Biochem. 1978, 91, 599-608.

(26) Rizzuto, R.; Pozzan, T. Physiol. Rev. 2006, 86, 369-408.

(27) Lee, M. H.; Park, N.; Yi, C.; Han, J. H.; Hong, J. H.; Kim, K. P.; Kang, D. H.; Sessler, J. L.; Kang, C.; Kim, J. S. J. Am. Chem. Soc. 2014, 136, 14136-14142.

(28) Matsuyama, S.; Reed, J. C. Cell Death Differ. 2000, 7, 1155-1165.

(29) Youle, R. J.; Narendra, D. P. Nat. Rev. Mol. Cell Biol. 2011, 12, 914

(30) Zhou, H.; He, L.; Xu, G.; Chen, L. Clin. Chim. Acta 2020, 507, 210-218.

(31) Clark, E. H.; Vazquez de la Torre, A.; Hoshikawa, T.; Briston, T. J. Biol. Chem. 2021, 296, 100209.

(32) Cai, Q.; Jeong, Y. Y. Cells 2020, 9, 150.

(33) Vara-Perez, M.; Felipe-Abrio, B.; Agostinis, P. Cells 2019, 8, 493.

(34) Li, P.; Xiao, H.; Cheng, Y.; Zhang, W.; Huang, F.; Zhang, W.; Wang, H.; Tang, B. Chem. Commun. 2014, 50, 7184.

(35) Chen, Y.; Zhu, C.; Cen, J.; Bai, Y.; He, W.; Guo, Z. Chem. Sci. 2015, 6, 3187-3194.

(36) Wu, M.-Y.; Li, K.; Liu, Y.-H.; Yu, K.-K.; Xie, Y.-M.; Zhou, X.-D.; Yu, X.-Q. Biomaterials 2015, 53, 669-678.

(37) Sarkar, A. R.; Heo, C. H.; Xu, L.; Lee, H. W.; Si, H. Y.; Byun, J. W.; Kim, H. M. Chem. Sci. 2016, 7, 766-773.

(38) Cao, L.; Zhao, Z.; Zhang, T.; Guo, X.; Wang, S.; Li, S.; Li, Y.; Yang, G. Chem. Commun. 2015, 51, 17324-17327.

(39) Li, G.; Zhang, B.; Song, X.; Xia, Y.; Yu, H.; Zhang, X.; Xiao, Y.; Song, Y. Sens. Actuators, B 2017, 253, 58-68.

(40) Liu, X.; Wang, L.; Bing, T.; Zhang, N.; Shangguan, D. ACS Appl. Bio Mater. 2019, 2, 1368-1375.

(41) Wilson, L. T.; Tipping, W. J.; Jamieson, L. E.; Wetherill, C.; Henley, Z.; Faulds, K.; Graham, D.; Mackay, S. P.; Tomkinson, N. C. O. Analyst 2020, 145, 5289-5298.

(42) Hu, F.; Zeng, C.; Long, R.; Miao, Y.; Wei, L.; Xu, Q.; Min, W. Nat. Methods 2018, 15, 194-200.

(43) Zeng, C.; Hu, F.; Long, R.; Min, W. Analyst 2018, 143, 48444848.

(44) Yamakoshi, H.; Palonpon, A.; Dodo, K.; Ando, J.; Kawata, S.; Fujita, K.; Sodeoka, M. Bioorg. Med. Chem. Lett. 2015, 25, 664-667.

(45) Zielonka, J.; Joseph, J.; Sikora, A.; Hardy, M.; Ouari, O.; VasquezVivar, J.; Cheng, G.; Lopez, M.; Kalyanaraman, B. Chem. Rev. 2017, 117, 10043-10120.

(46) Yamakoshi, H.; Dodo, K.; Palonpon, A.; Ando, J.; Fujita, K.; Kawata, S.; Sodeoka, M. J. Am. Chem. Soc. 2012, 134, 20681-20689.

(47) Poot, M.; Zhang, Y. Z.; Krämer, J. A.; Wells, K. S.; Jones, L. J.; Hanzel, D. K.; Lugade, A. G.; Singer, V. L.; Haugland, R. P. J. Histochem. Cytochem. 1996, 44, 1363-1372.

(48) Thomas, J. A.; Buchsbaum, R. N.; Zimniak, A.; Racker, E. Biochemistry 1979, 18, 2210-2218.

(49) Sica, V.; Izzo, V.; Bravo-San Pedro, J. M.; Zamzami, M.; Maiuri, M. C. In Autophagy: Cancer, Other Pathologies, Inflammation, Immunity, Infection, and Aging; Academic Press: Cambridge MA, 2016; pp 91104.

(50) Hytti, M.; Korhonen, E.; Hyttinen, J. M. T.; Roehrich, H.; Kaarniranta, K.; Ferrington, D. A.; Kauppinen, A. Oxid. Med. Cell. Longevity 2019, 2019, 1-12.

(51) Joseph, L. C.; Barca, E.; Subramanyam, P.; Komrowski, M.; Pajvani, U.; Colecraft, H. M.; Hirano, M.; Morrow, J. P. PLoS One 2016, 11, e0145750.

(52) Moon, Y.; Lee, K. H.; Park, J.-H.; Geum, D.; Kim, K. J. Neurochem. 2005, 93, 1199-1208. 
(53) Selivanov, V. A.; Zeak, J. A.; Roca, J.; Cascante, M.; Trucco, M.; Votyakova, T. V. J. Biol. Chem. 2008, 283, 29292-29300.

(54) Matsuyama, S.; Llopis, J.; Deveraux, Q. L.; Tsien, R. Y.; Reed, J. C. Nat. Cell Biol. 2000, 2, 318-325. 